\title{
La «mujer cerrada»: La impotencia femenina en la Edad Media y el peritaje médico-legal de las parteras
}

\author{
Paloma Moral de Calatrava (*) \\ (*) Departamento de Enfermería. Universidad de Murcia \\ pmoral@um.es
}

SUMARIO: 1.-Introducción. 2.-Cirugía para la clausio matricis. 3.-Mujeres de buena fama para el examen físico femenino. 4.-Conclusiones.

RESUMEN: Las relaciones sexuales fueron establecidas en el siglo XIII como un requisito para confirmar o anular un matrimonio. De modo que cuando una mujer era acusada de no ser físicamente capaz de cumplir con sus obligaciones maritales sexuales, un grupo de mujeres tenían que inspeccionar el cuerpo de la esposa buscando signos de virginidad. Este trabajo estudia el papel médico y legal de las parteras en esos casos. Los textos médicos latinos y los escritos en lengua vernácula muestran que hubo dos posturas sobre quién debía realizar una cirugía diseñada para recuperar la potencia sexual perdida: la partera o el cirujano. La Iglesia, sin embargo, no siempre obligó a las «mujeres cerradas o impotentes» a someterse a esta intervención quirúrgica, sino que eventualmente permitió la separación de la pareja. Los textos son ambiguos sobre quién tenía que realizar el examen del cuerpo femenino, si parteras o, simplemente, mujeres honestas. Los decretos eclesiásticos medievales utilizan palabras como matrona o mujer, pero en este trabajo se postula que lo habitual es que se tratara de parteras.

PALABRAS CLAVE: parteras, impotencia femenina, decretales, cirugía medieval, derecho matrimonial.

KEY WORDS: Midwives, female impotence, decrees, mediaeval surgery, marriage law.

\section{Introducción $(*)$}

¿Por qué en la Edad Media la Iglesia consideraba no sólo permisible, sino necesario, el sexo en el matrimonio? El fin plausible del matrimonio cristiano

(*) Esta investigación se enmarca en los proyectos HAR2009-07139 del MICINN y 08827/PHCS/08 de la Fundación Séneca. 
era la continuación de la especie, la procreatio prolis, pero ¿qué sucedía si la pareja era impotente para consumar el matrimonio? En ese caso tampoco era aconsejable pretender la castidad, porque la otra finalidad del sexo en el matrimonio era precisamente la sedatio concupiscentiae, que evitaba la tentación de la fornicación y el pecado mortal de la lujuria. Sin embargo, esta última justificación del sexo en el matrimonio trajo consigo no pocos problemas teológicos. En general, el matrimonio cristiano se consideraba indisoluble cuando los contrayentes se aceptaban públicamente en la Iglesia y, después, sellaban la unión con la consumación sexual ${ }^{1}$. Pero el matrimonio modélico para los cristianos era un matrimonio inconsumado, el de los padres de Jesucristo, al que las Escrituras nos presentan como un matrimonio casto $^{2}$. ¿Era Jesús, entonces, un hijo ilegítimo? Los argumentos para rebatir, o al menos sortear, una respuesta positiva a esta cuestión, dieron lugar a una abundante literatura doctrinal sobre el matrimonio cristiano $^{3}$. La importancia del coito en la formación del matrimonio cristiano y las consecuencias para quienes no pudieran cumplir con la deuda carnal fueron definitivamente establecidas en 1234, cuando Raimundo de Penyafort concluyó la compilación de leyes de la Iglesia que le había encargado el Papa Gregorio IX, más conocidas como Decretales de Gregorio IX o Liber extra ${ }^{4}$. La incapacidad para cumplir con el débito conyugal sería, desde entonces, una de las principales causas para anular un matrimonio. Pero, obviamente, no era lo mismo que la incapacidad sexual residiera en el hombre o en la mujer. Los hombres podían ser impotentes por causas naturales o como consecuencia de un maleficio. Mientras que los diagnosticados de incapacidad natural no podrían contraer matrimonio alguno,

1. Resnick Irven. Marriage in medieval culture: consent theory and the case of Joseph and Mary. Church History. 2000; 69 (2): 350-371.

2. Gold, Penny. The marriage of Mary and Joseph in the twelfth-century ideology of marriage. In: Bullough, Vern; Brundage, James, eds. Sexual practices and the medieval church. New York: Prometheus; 1994, p. 102-117.

3. Brundage, James. La ley, el sexo y la sociedad cristiana en la Europa Medieval. México D.F.: FCE; 2000.

4. Utilizo, para su comparación, los textos latino y castellano de las Decretales. Este texto se divide en cinco libros, cada uno se subdivide en títulos, que están compuestos por capítulos. Siguiendo la citación moderna aparece el libro en número romano, y el título y el capítulo que cito en números arábigos. Decretalium Collectiones. Friedberg, Aemilius, ed. Graz: Akademische Druck; 1959; Decretales de Gregorio IX. Mans Puigarnau, Jaime, ed. Barcelona: Universidad de Barcelona; 1939; Penyafort, Raimundo de. Summa on Marriage. Payer, Pierre, trad. Toronto: Pontifical Institute of Medieval Studies; 2005. 
los hechizados que sufrían impotencia mágica podían volver a casarse, ya que se les suponía impotentes sólo con la actual esposa ${ }^{5}$. Por su lado, las mujeres que eran fisiológicamente incapaces de consumar el matrimonio, llamadas «mujeres cerradas», sólo tenían dos posibilidades: ingresar en un convento y renunciar a tener vida sexual, o tratar de abrir sus zonas íntimas con el propósito de formalizar el matrimonio. Desde el siglo XIII, los tribunales eclesiásticos se enfrentaron al reto de determinar quién de los dos - el hombre o la mujer - era incapaz de prestar el débito conyugal, y para ello un grupo de mujeres inspeccionaba el cuerpo de la esposa en busca de signos de virginidad. Así pues, el establecimiento de la capacidad sexual fue un requisito imprescindible para valorar el estado sacramental del matrimonio, y que la medicina contara con el arsenal diagnóstico y terapéutico adecuado para diagnosticar y resolver la impotencia fue una cuestión crucial en el contexto social de la Edad Media.

El objetivo de este trabajo es poner de relieve las competencias médicas y jurídicas de las parteras en aquellos casos en los que una mujer no podía mantener relaciones sexuales con su marido para confirmar el matrimonio. Para ello analizo, en primer lugar, los tratamientos que fueron diseñados para que las mujeres pudieran ofrecer el débito conyugal. El estudio pormenorizado de las fuentes médicas muestra que en la Edad Media se desarrollaron dos discursos sobre quién debía ejecutar el procedimiento: la partera o el cirujano. Las fuentes tardoantiguas y sus epígonas árabes con frecuencia consideraban a la partera la responsable de este peritaje, pero la profesionalización de la medicina en la Baja Edad Media tuvo como consecuencia el soslayamiento de las competencias de las parteras sobre el cuerpo femenino. A pesar de que Monica Green ya demostró que en la Edad Media la práctica médica femenina no se circunscribió a la obstetricia ${ }^{6}$, las fuentes se resistieron a calificar las actividades terapéuticas y de cuidados que las mujeres llevaron a cabo. A esta dificultad intrínseca de las fuentes, hay que sumarle las consecuencias provenientes de las estructuras patriarcales medievales. La exclusión de las mujeres de la institución universitaria y de las

5. Brundage, James. The problem of impotence. In: Bullough; Brundage, n. 2, p. 135-140; Boccafola, Kenneth. The requeriment of perpetuity for the impediment of impotence. Roma: Università Gregoriana; 1975, p. 25-28.

6. Green, Monica. Women's medical practice and health care in Medieval Europe. Signs. 1989; 14 (2): 434-437 [reimp. Green, Monica. Women's health care in the Medieval West. Texts and contexts. Aldershot: Ashgate; 2000, I.]. 
organizaciones para el ejercicio médico, favoreció que éstas se transmitieran oralmente sus conocimientos, lo que provocó no pocas sospechas y recelos sobre la legitimidad moral de los métodos que empleaban. En este contexto los médicos buscaron consolidar una imagen ideal de hombre honesto y sabio, que provocó la desvalorización progresiva de la práctica médica femenina ${ }^{7}$.

El tratamiento quirúrgico estuvo disponible, pero la Iglesia no obligó a las mujeres cerradas a someterse a tal cirugía. De acuerdo con la legislación eclesiástica que se analiza en la segunda parte de este trabajo, fue preciso que se sometieran a un examen físico ante unas «matronas» (matronae) que debían cumplir un requisito principal: ser honestas; y sólo eventualmente se añadía «y sabias». Mientras que en lenguas como el castellano actual a las parteras se les llama matronas, con frecuencia se han planteado razonables dudas sobre si en la Edad Media el término latino matrona se puede identificar con el de obstetrix. A través del examen de fuentes médicas y jurídicas, el presente artículo pretende contribuir a dar respuesta a tres preguntas: ¿Cuál fue el papel que cumplieron las matronas en la Baja Edad Media en los casos de impotencia?, ¿qué funciones médicas y legales desempeñaron? y ¿cómo evolucionó en esa época la terminología para designar al oficio de partera? A partir del siglo XIII las fuentes médicas y la legislación eclesiástica trataron de circunscribir las actividades sanitarias femeninas a la obstetricia, excluyéndolas de la ginecología. Como veremos, en la práctica las parteras jugaron un importante papel en el diagnóstico y tratamiento de las mujeres cerradas.

\section{Cirugía para la clausio matricis}

Una causa a la que se podría haber atribuido la atresia femenina (clausio matricis) sería la dureza del himen, pero lo cierto es que esta estructura

7. Dangler, Jean. Mediating fictions. Literature, women healers, and the go-between in Medieval and Early Modern Iberia. Lewisburg: Bucknell University Press; 2001; Cabré, Montserrat; Salmón, Fernando. Poder académico versus autoridad femenina: la Facultad de Medicina de París contra Jacoba Félicié (1322). Dynamis. 1999; 19: 55-78; Salmón, Fernando; Cabré, Montserrat. Fascinating women: The evil eye in medical scholasticism. In: French, Roger et al., eds. Medicine from the black death to the French disease. Ashgate: Aldershot; 1998, p. 53-84; Cabré, Montserrat. "Como una madre, como una hija»: Las mujeres y los cuidados de salud en la Baja Edad Media. In: Morant, Isabel, dir. Historia de las mujeres en España y América Latina. Madrid: Cátedra; 2005, p. 637-657; Harper, April. The image of the female healer in Western vernacular literature of the Middle Ages. Social History of Medicine. 2011; 24 (1): 108-24. 
anatómica, relacionada más tarde con la virginidad, no fue descrita por la medicina grecorromana ${ }^{8}$. Galeno no identificó el himen porque para describir la anatomía genital de las mujeres tomó como modelo al cuerpo masculino9; Sorano negó su existencia, si bien consideró la posibilidad de que las mujeres no pudieran mantener contactos carnales como consecuencia del desarrollo de una indeterminada membrana ${ }^{10}$. El himen no fue descrito por los médicos de la Antigüedad como una parte de la anatomía femenina, pero la intervención para las mujeres cerradas sí está presente en las grandes obras médicas. Los tratados hipocráticos ${ }^{11}$, Celso $^{12}$, Oribasio ${ }^{13}$, Sorano ${ }^{14}$, Aecio de Amida ${ }^{15}$ o Pablo de Egina ${ }^{16}$ describieron distintas formas de acometer una cirugía cuya entidad nosológica recaía fuera del cuerpo femenino. Es decir, no describieron el problema en función de los signos y síntomas con los que se presentaba en las mujeres, porque el motivo y propósito de la intervención era hacer sexualmente accesible su cuerpo a los hombres, que pudieran concebir hijos y adquirir así el estatus de madres. Parece que el himen no fue descrito como una estructura anatómica normal, pero fue tratado cuando constituía un problema.

8. Lastique, Esther; Lemay, Helen. Medieval physician's guide to virginity. In: Salisbury, Joyce, ed. Sex in the Middle Ages. A book of essays. New York: Garland Publishing; 1991, p. 56-79 (58).

9. Galeno. De usu partium, XIV; Galen. On the usefulness of the parts of the body. Tallmadge May, Margaret, trad., vol 2, p. 628-629; Sissa, Giulia. Une virginité sans hymen: Le corps féminin en Grèce ancienne. Annales. Histoire, Sciences Sociales. 1984; 39 (6): 1119-1139; Sissa, Giulia. La verginità in Grecia. Bari: Laterza; 1992, p. 99-105.

10. Sorano. Ginecología I, 3, 17; Soranus' gynecology. Temkin, Owsey, trad. Baltimore-London: The Johns Hopkins University Press; 1956, p. 15.

11. Tratados Hipocráticos. Sanz Mingote, Lourdes, trad. y notas; Ochoa Anadón, José Antonio, introd. e índices, vol. 4, Madrid: Gredos; 1988: Sobre las enfermedades de las mujeres I = Mul. I, 13, p. 13; Sobre las enfermedades de las mujeres II = Mul. II, 163, 181, p. 255 y 267; Sobre las mujeres estériles = Ster., 11 [223], Ster., 11 [225], Ster., 23 [235], p. 306, 308 y 317; Sobre la superfetación = Superf., 29, 32, p. 342 y 345; Sobre la naturaleza de la mujer = Nat. Mul., 21, p. 345 .

12. Celso. De medicina, VII. 8. Los ocho libros de medicina. Blánquez, Agustín, trad., vol. 2. Barcelona: Iberia; 1966, p. 218-219.

13. Oribasio. Colecciones médicas, XXIV. 32. Medici Bizantini. Oribasio di Pergamo, Aezio d'Amida, Alessandro di Tralle, Paolo d'Egina, Leone medico. Garzya, Antonio et al., eds. Torino: Editrice Torinese; 2006, p. 138-141.

14. Sorano, n. 10, p. 15.

15. Aecio de Amida. Tetrabiblion, XVI. 96. Aetios of Amida. Gynecology and obstetrics of the VIth century. Ricci, James, trad. Philadelphia: Blakiston; 1950, p. 103-104.

16. Pablo de Egina. VI, 72. Egina, Paolo di. Studi sulla chirurgia bizantina. Tabanelli, Mario, trad. Firenze: Olschki; 1964, p. 79-80. 
Las causas que impedían a un hombre conocer carnalmente a una mujer fueron, básicamente, dos: la presencia de una membrana o el crecimiento de un añadido carnoso que impedía el coito y cerraba el paso al semen masculino, impidiendo el embarazo y el parto ${ }^{17}$. Esta obstrucción podía desarrollarse en los labios vaginales, en la parte intermedia de la vagina o junto al cérvix, y el lugar en el que crecía condicionaba, según Muscio - que versionó al latín en el siglo VI la Ginecología de Sorano- las funciones propias de las mujeres: el contacto sexual, la concepción y la menstruación. Si esta membrana crecía de forma externa la mujer no podía desempeñar ninguna de ellas; si lo hacía en medio de la vagina sólo podía menstruar; pero si se desarrollaba cerca del cérvix ni podía menstruar ni concebir, aunque era apta para mantener relaciones sexuales ${ }^{18}$.

La cuestión de quiénes ejecutaban esta intervención, hombres o mujeres, es difícil de resolver. Pese a que la operación fuera infrecuente, tuvo entidad suficiente como para aparecer en las obras médicas más prestigiosas. A excepción de Muscio, ninguna fuente tardoantigua menciona la necesidad de contar con mujeres como ejecutoras de la cirugía, pero en la Edad Media el hecho de tener que inspeccionar e intervenir en los genitales femeninos planteó un problema moral. Las fuentes medievales citan de forma explícita la presencia de la obstetrix como ejecutora de procedimientos que requerían tocar los genitales femeninos - como la sofocación uterina, el parto o la extracción del feto muerto-, pero en el caso de la mujer cerrada hubo dos tendencias relacionadas con quién debía ejecutar el tratamiento: la primera de ellas afirma explícitamente que las parteras realizan la inspección y la cirugía, la segunda parece defender que médicos y cirujanos eran los actores legítimos en la intervención.

Entre quienes sostienen que era una mujer quien realizaba el diagnóstico y practicaba la cirugía destacan Muscio, Albucasis y Constantino el Africano (traduciendo a al-Mağūsī). En el occidente latino la Genecia de Muscio fue la obra más importante para el tratamiento del cuerpo femenino hasta las traducciones de Albucasis y al-Mağūsī en los siglos XI y XII ${ }^{19}$. Muscio resumió la obra de Sorano con el objeto de hacerla accesible a las

17. Pablo de Egina, n. 16, p. 80.

18. Muscio. Gynaecia, II. 33. Radicchi, Rino, trad. Pisa: Giardini; 1970, p. 204.

19. Hanson, Ann; Green, Monica. Soranus of Ephesus: Methodicurum Princeps. In: Haase, Wolfgang; Temporini, Hildegard, eds. Aufstieg und Niedergang der Römischen Welt. II: Prinkipat. Vol. 37. t. 2. Berlin: Walter de Gruyter, 1994, p. 969-1075 (1054). 
parteras y le dio un formato de pregunta-respuesta, según él para acomodar la teoría ginecológica a la capacidad intelectual femenina. El problema de la clausio matricis aparece en el segundo libro, que tiene mayor contenido teórico, y en él especifica que para el diagnóstico la partera debe utilizar diversos procedimientos: usará la vista cuando la membrana crezca en la parte externa, el tacto cuando aparezca en medio de la vagina y el espéculo cuando se sitúe en el orificio interno de la matriz. Además de preguntar qué funciones impide realizar - menstruar, concebir o mantener relaciones sexuales - la partera debe estudiar si el problema se debe a una membrana, que sólo debe rasgar con un bisturí, o si hay una excrecencia carnosa, que debe extirpar completamente. Si la mujer no tiene menstruaciones, es necesario dejar escapar la sangre acumulada y, en todos los casos, tras la intervención debía realizar una cura que favoreciera la cicatrización ${ }^{20}$. Albucasis, por su parte, menciona de forma explícita la presencia femenina en el tratamiento de casos de mujeres cerradas; ellas debían distinguir la naturaleza del tejido que impedía el coito, el lugar en el que se desarrollaba y seguir procedimientos diferentes en función de esos dos criterios. Parece que Pablo de Egina fue su fuente principal, pero, a diferencia del bizantino, el cordobés señala explícitamente a las mujeres como las ejecutoras de la cirugía $^{21}$. Albucasis explica por qué un cirujano necesita que una mujer realice una operación en los genitales femeninos en el capítulo que dedica a la extracción de la piedra en la vejiga. Las reticencias a que un hombre realizara la intervención provenían de las propias afectadas, que podían ser vírgenes, no querer exponer sus zonas íntimas a un hombre o necesitar una incisión profunda (sin explicar por qué la profundidad de la incisión es un criterio que determina la participación femenina en la cirugía) ${ }^{22}$. La Cirugía de Constantino el Africano, que se corresponde con el capítulo IX de la «Práctica» del Pantegni que traduce de al-Mağūsī ${ }^{23}$, parece que

\footnotetext{
20. Muscio, n. 18, p. 204-210.

21. Albucasis. On surgery and instruments. Spink, Martin; Lewis, Geoffrey, eds. Berkeley: University of California Press; 1973, p. 458-460; Albucasis. Liber theoricae necnon practicae Alsaharavii Augusta Vindelicorum: Grimm, Sigismundus; Wirsung, Marcus; 1519, fol. 107. col.a.

22. Albucasis, n. 21, p. 420. En casos de hermafroditismo y escisión del clítoris, dos problemas en los que inevitablemente se tocaban los genitales, no alude a la presencia femenina. Albucasis, n. 21, p. $454,456$.

23. Green, Monica. The re-creation of Pantegni, Practica, Book VIII. In: Burnett, Charles; Jacquart, Danielle, eds. Constantine the African and 'Alī ibn al-'Abbās al-Mağūsī. Leiden: Brill; 1994, p. 121-160 (122-124).
} 
también deriva en lo fundamental de la obra del Egineta. Pero si Albucasis justifica las causas por las que se necesita que las mujeres intervengan en los genitales femeninos, para Constantino la explicación es superflua, y menciona a la partera exclusivamente en los capítulos de la clausio matricis, las apostemas de la vulva, la extracción del feto y la placenta y el ano imperforado de los recién nacidos ${ }^{24}$.

Si hasta el siglo XI las fuentes parecen ser homogéneas a la hora de identificar a las parteras como las que practican la intervención, en el XII se inicia un cambio de tendencia. Esteban de Antioquía, en 1127, volvió a traducir a al-Mağūsī para realizar una versión más fiel al original y, como Constantino, afirmó que era la obstetrix quien realizaba la inspección y la cirugía ${ }^{25}$. Sin embargo en el Breviarium de la segunda mitad del XII de Johannes de Sancto Paulo, el primer médico salernitano en referirse a este problema, la figura de la partera fue sustituida por el genérico término de «mujer» (mulier) —vocablo que respeta en el capítulo de la sofocación uterina- ${ }^{26}$.

En la medicina escolástica se dio un paso más y se consolidaron las autoridades médicas que consideraban a los galenos los únicos intervinientes legítimos en casos de mujeres cerradas, obviando a la obstetrix. El Canon de Avicena, aun sin modificar el modo de realizar la operación, hizo explícita la necesidad de que fuera el medicus quien la ejecutara ${ }^{27}$. Ésta fue una modificación sustancial, y su influencia en la medicina europea no debe ser pasada por alto. Aunque la operación para las mujeres cerradas debió ser infrecuente, apareció en los manuales de cirugía más prestigiosos de la Edad Media. Lanfranco de Milán sólo introdujo en su Cirugía dos capítulos sobre los problemas femeninos: uno dedicado a las afecciones del pecho y otro en el que aunó el hermafroditismo con el problema del útero imperforado ${ }^{28}$.

24. Costantino I' Africano. Chirurgia. Malato, Marco; Loria, Luigi, trads. Roma: Università di Roma; 1960, p. 55-57, 123-126; Green, n. 23, p. 126, 155 y 159. Como Albucasis, no alude a la obstetrix en el hermafroditismo femenino.

25. Stephanus Antiochenus. Liber totius medicine necessaria. Michael de Capella, ed. Lugduni: Jacobi Myt; 1523.

26. Green, Monica. Making women's medicine masculine. The rise of male authority in pre-modern gynaecology. Oxford: Oxford University Press; 2008, p. 40 y 43.

27. Avicena, Liber Canonis. Hildesheim: Georg Olms; 1964 [reimp. facsímil Venettis 1507], Trac. IIII, fen. XXI, c. I, II, III, fols. 374-375.

28. Lanfranco. Practica que dicitur ars completa totius chirurgiae. In: Ars chirurgica Guidonis Cauliaci, Venetiis: Giunta; 1546, fol. 245v; Albi Romero; Guadalupe, ed. Lanfranco de Milán en España. Estudio y edición de la Magna Chirurgia en traducción castellana medieval. Valladolid: Universidad de Valladolid; 1988, p. 320-321. 
Guy de Chauliac, de acuerdo con Albucasis, diferenció entre el hermafroditismo, el tentigo - el clítoris- y la clausio en su Cirugía de $1363^{29}$. Para el milanés y el montepulsiano, omitiendo a la partera, el cirujano era quien debía valorar la membrana, elegir el instrumento a utilizar y realizar la operación. Ambos dicen así:

«Estonce, ata la muger, segund que deximos enel fendimiento de la piedra debe ser fecho, e estonce abre el coño o vulva con tenazas, porque puedas ver el orificio de la madriz e quita todas las cosas demasiadas con instrumentos, guardando muy mucho que non tangas a la sustançia de la madriz, antes es mejor que dexes alguna cosa de los superfluo que non quites porfincadamente. E despues, ten forma de verga fecha de plomo gruessa, quanto puedes meter, la qual unta con olio de lirio; e empuxala fasta el orifiçio de la madriz; e dexala ende fasta que el lugar sea firmado de cada parte. $\mathrm{E}$ ende, use la compañia del varon, untado primeramente el lugar con enxundia de ansar o de gallina $»^{30}$.

«La curacion es vna con cortamiento si fuere carne añadida con nauaja, o con ligamento con filo. Mas si fuere con piel o cuero con las vñas sea abierto, o con la nauaja e tenta canulada de madero o plomo vntada con manteca. O con el azeite por que pueda mear. O tenta firme el paño a modo de pequeña verga o vara sea puesta muchas vezes aquella remude, o vse de coytu, o copula, porque no sea tornada a ençerrar» ${ }^{31}$.

Pero el tratamiento para las mujeres cerradas no fue territorio exclusivo de cirujanos. Algunos médicos, ofrecieron el uso de baños y pesarios

29. Guidonis de Cauliaco. Inventarium sive Chirurgia Magna. McVaugh, Michael, ed., vol. 1. LeidenNew York: Brill; 1997, p. 387-388. Aunque para la cirugía del hermafroditismo y la extirpación del clítoris inevitablemente se tocaban los genitales femeninos, ninguna fuente menciona la necesidad de que una mujer realizara la cirugía. Ambos problemas están relacionados con el de la mujer cerrada, ya que los tres pueden impedir las relaciones sexuales femeninas (y en las fuentes se tratan de forma consecutiva), pero en los dos primeros casos la ausencia de la figura femenina ejecutando la inspección y la intervención los deja fuera de nuestro análisis.

30. Lanfranco, 1988 , n. 28, p. 321; Lanfranco, 1546, n. 28, fol. 245v.

31. Guy de Chauliac. Tratado de cirugía. In: Herrera, M.a Teresa; González de Fauve, Estela, eds. Textos y concordancias del Corpus Médico Español [CD-ROM]. Madison: Hispanic Seminary of Medieval Studies; 1997, fol. 160r. En la versión medieval española no se menciona a Albucasis como fuente, pero sí en la latina. Cauliaco, n. 29, p. 387. 
como posible cura ${ }^{32}$, como Bernardo Gordonio, coetáneo de Chauliac en Montpellier, así como los textos prácticos que se derivaron de su Lilium medicinae: el Tractatus de sterilitate ${ }^{33}$, el Tractatus de sterilitate mulierum ${ }^{34} \mathrm{y}$ el Tractatus de conceptu ${ }^{35}$. A pesar de que el procedimiento requería tocar los genitales de las mujeres, el Lilium no menciona la necesidad de contar con la ayuda de ninguna mujer con mayor o menor nivel de destreza en los cuidados de este problema de salud femenina.

Ciertos cirujanos - como Lanfranco o Chauliac-, al omitir la figura de la partera, parecen defender la necesidad de que sean los que ejercen su propia profesión quienes ejecuten la operación. Pero también los médicos propusieron tratamientos complementarios a la cirugía. Sin embargo, el hecho de que tuvieran que acceder a los genitales femeninos no debió de ser un problema menor. Lo que las fuentes parecen indicar es que la profesionalización de la medicina y la cirugía, la inclusión de los estudios médicos en la Universidad y la escasa incidencia de este problema de salud femenina, jugaron un papel importante en la supresión de la partera como agente de su diagnóstico y tratamiento. Lanfranco incluyó en su tratado diversos aspectos tomados de la cirugía ginecológica de Avicena y Albucasis, pero prescindió de esas fuentes de autoridad en la intervención para las mujeres cerradas para seguir a su maestro Guillermo de Saliceto, al considerar que los hombres podían intervenir en los genitales femeninos cuando utilizaban instrumental ${ }^{36}$. Chauliac, sin embargo, fue más allá: en el epígrafe dedicado a la clausio matricis citó a Albucasis, pero omitió deliberadamente a la partera, figura que sin embargo cita en los procedimientos relacionados con el parto ${ }^{37}$.

32. Bernardo Gordonio. Lilio de medicina. Dutton, Brian; Sánchez, M. a Nieves, eds., vol. 2. Madrid: Arco; 1993, p. 1499-1500.

33. Tractatus de sterilitate. Monterlo Cartelle, Enrique, ed. Valladolid: Universidad de Valladolid; 1993, p. 80-83.

34. Tractatus de sterilitate mulierum. Conde Parrado, Pedro; Montero Cartelle, Enrique; Herrero Ingelmo, M. ${ }^{a}$ Cruz, eds. Valladolid: Universidad de Valladolid; 1999, p. 154-157.

35. Tractatus de conceptu. Conde Parrado, Pedro; Montero Cartelle, Enrique; Herrero Ingelmo,

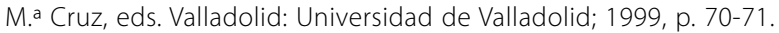

36. Green, n. 26, p. 98-100.

37. La matrona aparece en el capítulo de la inspección de la impotencia masculina, y la obstetrix se halla únicamente en los capítulos titulados extraccio fetus, vivo o muerto, y extraccio secundine. No aparece la obstetrix en el capítulo sobre la mola ni De exitu matricis et longaonis. Parece clara la intención de Chauliac de circunscribir la tarea de las parteras al área obstétrica y apartarlas de la ginecológica. Cauliaco, n. 29, p. 388-389. 
Los textos de la Baja Edad Media muestran la convivencia de las dos posiciones sobre quién debía realizar este tipo de cirugía: si los textos de la medicina académica suelen evitar la figura de la partera, las obras de Muscio, Constantino y Albucasis la mencionan de modo explícito. Sin embargo, la tendencia surgida en el ámbito de la medicina más cercana a la Universidad no logró suprimir la referencia a las mujeres realizando la inspección genital y practicando la cirugía. De hecho, en la literatura médica en lenguas vernáculas, coetánea de los citados textos médicos escritos en latín, se sigue mencionando a la partera de modo explícito. Por ejemplo, en la traducción francesa de la obra de Albucasis del siglo XIII ${ }^{38}$, la partera no fue sustituida por el médico o cirujano, y el autor anónimo de una obra de medicina general que redactó su compilación en castellano en el siglo XV, corroboró la necesidad de que una partera inspeccionara con su instrumental los genitales y realizara la intervención. El breve capítulo sobre «la cerrada» dice así:

«Será de dos maneras: o natural o açidental. E el natural es lo que naçio la muger con la madre con forada. E el açidental es lo que se fizo por llaga vieja en el cuello de la madre e arriba entre esos logares: e sera por pegada o por apretadura o sera carne o tela o dolençia. E esta dolençia veda al varon de non pasar a ella njn se puede priuar e quiça quel vedara su tienpo. E la su señal es que lo vedara la partera a ojo, escodriñando con su dedo o con su cala. E la cura es que se moje menchas de llino en vnguento de cardenjello e pongalas y [ahí]; e sy comjere esa tella o esa carne, pon despues en el forado canudo hueco de plomo o non lo tire algunos dias; e pase a ella el varon despues que non se solde. E sy conpliere esto non obre con las manos, segunt es dicho en el libro de la çirugia» ${ }^{39}$

Aunque la medicina y la cirugía desarrollaron procedimientos para solventar la clausio matricis, la Iglesia daba al matrimonio la opción de separarse, sin obligar a las mujeres cerradas a someterse a la intervención. Para ello, la legislación eclesiástica exigió que un grupo de mujeres, a las que llamó usualmente «matronas», realizara un examen pericial. ¿Eran estas matronas expertas parteras (obstetrices), o simplemente «mujeres

38. Albucasis. Traitié de cyrurgie. Édition de la traduction en ancien français de la Chirurgie d'Albu'l Qasim Halaf Ibn 'Abbas al-Zahrawi du manuscrit BNF, 1328. Trotter, David, ed. Tübingen: Max Niemeyer; 2005, p. 142-143.

39. Herrera, M. ${ }^{a}$ Teresa; Sánchez, M. ${ }^{a}$ Nieves, eds. Tratado de patología. Madrid: Arco; 1997, p. $720-$ 721. La cursiva es mía. 
honestas»? La Iglesia diseñó un procedimiento jurídico en el que aparentemente no era imprescindible que participaran mujeres con conocimientos cualificados sobre el cuerpo femenino. Quiénes eran estas mujeres y qué requisitos debían cumplir son cuestiones en las que no existe consenso, y por ello merecen un análisis detallado.

\section{Mujeres de buena fama para el examen físico femenino}

A pesar de que en la literatura médica grecorromana no apareciera el himen, desde épocas muy tempranas el cristianismo aceptó la inspección corporal para corroborar la virginidad femenina. El concepto de virginidad iba más allá de la abstinencia sexual, y era preciso que las mujeres mantuvieran un determinado estilo de vida ${ }^{40}$, por ello san Agustín afirmó que la pérdida de la integridad vaginal durante el examen de una obstetrix no implicaba que una mujer dejara de ser virgen ${ }^{41}$. La idea de la existencia de un tejido que proporcionaba la prueba física de la virginidad fue introducida en la medicina europea bajo la influencia de Razés y Avicena ${ }^{42}$, aunque siguió sin recibir una entidad anatómica que permitiera identificarlo con el problema de la estrechez vaginal ${ }^{43}$. La presencia del himen fue un signo objetivo para declarar la nulidad matrimonial, y las vírgenes debían mostrar sus cuerpos a un grupo de mujeres que testificarían ante el tribunal eclesiástico. Pero la validez de su testimonio fue puesta en entredicho por algunos hombres preeminentes, como Alberto Magno, que advirtió que había mujeres que utilizaban ciertos medicamentos para crear la falsa apariencia de virginidad ante un examinador inexperto ${ }^{44}$. De modo que la buena fama de estas mu-

40. John Chrysostom. On virginity. In: Cox Miller, Patricia, ed. Women in early christianity: translations from greek texts. Washington: The Catholic University of America Press; 2005, p. 117; Kelly, Kathleen C. Performing virginity and testing chastity in the Middle Ages. London: Routledge; 2000, p. 34.

41. Agustín de Hipona. La Ciudad de Dios. Riber, Lorenzo, trad., vol.1. Barcelona: Alma Mater; 1959, I, 18.4, p. 41.

42. Le livre intitulé Al-Manșūrī sur la médicine par Muhammad ibn Zakariyyā al-Razī. In: Koning, P. de, trad. Trois traités d'anatomie Arabes. Leiden: Brill; 1903, p. 89; Avicena, n. 27, Tract. II, fen. XXI, fol. 360vb.

43. Green, n. 26, p. 96

44. Albertus Magnus. De animalibus. Stadler, Hermanm, ed. Münster: Aschendorff; 1916, Lib. I. tract. II. cap. XXIV, p. 163. 
jeres fue un elemento esencial a la hora de elaborar el dictamen eclesiástico sobre la validez del matrimonio o su anulación.

La Iglesia cambió de parecer sobre la importancia de la consumación sexual y, por lo tanto, en lo relativo a las consecuencias sacramentales que se derivaban de la imposibilidad de que las mujeres cerradas pudieran ofrecerlo. Si Alejandro III (1159-1181) permitió la separación de un matrimonio por estrechez femenina, su sucesor Lucio III (1181-1185) consideró que el matrimonio bajo estas circunstancias era legítimo y, en consecuencia, podía permanecer unido ${ }^{45}$. En el siglo XIII la Iglesia utilizó, entre otros argumentos, razones médicas para articular el sacramento matrimonial, a veces de forma tan peregrina como el IV Concilio de Letrán (1215), que justificó la reducción del impedimento matrimonial del séptimo al cuarto grado de consanguinidad y afinidad, porque «cuatro son los humores del cuerpo» ${ }^{46}$. Los casos en los que las mujeres podían demostrar físicamente que eran vírgenes provocaban sospechas sobre la potencia viril, por eso Tomás de Aquino propuso, para los casos en los que la medicina no pudiera diagnosticar al marido de impotencia natural o mágica, que se practicara una intervención quirúrgica sobre la mujer y que, de esta forma, los esposos pudieran confirmar el matrimonio:

«No puede ser perpetuo el impedimento natural del varón cuando es respecto de una mujer, pero no lo es respecto de otra. Por tanto, si no puede verificar el coito con una virgen, y, sin embargo, puede con una desflorada, sería cuestión de romper el himen [claustra pudoris] con algún instrumento quirúrgico, para que se pueda realizar el coito. Y eso no sería antinatural, pues no se practicaría con vistas al deleite, sino por motivo de medicina» ${ }^{47}$

La forma de reparar la clausio matricis no debió ser parte de la experiencia normal de un cirujano, un médico o una partera ${ }^{48}$, no sólo por la

45. Decretales, n. 4, IV,15,4, p. 60; Decretalium, n. 4, IV,15,4, p. 705.

46. Tanner, Norman P., ed. Decrees of the Ecumenical Councils. London-Washington: Sheed \& Ward and Georgetown University Press; 1990, p. 257-258; Cirivilleri, Robert. Marriage and Canon law: Consanguinity, affinity and the Medieval church (996-1215). Ph. D. Dissertation. San Jose State University; 2000, p. 122-127.

47. Tomás de Aquino, Suma teológica. Barbado Viejo, Francisco, trad., vol. XV. Madrid: BAC; 1961 Supl. q58 a1, p. 454.

48. Green, n. 26, p. 105-106; Darmon, para los siglos XVII y XVIII, calcula que los casos de impotencia femenina ascendían a un 5\%. Darmon, Pierre. Trial by impotence: virility and marriage in pre-revolutionary France. London: The Hogarth Press; 1985, p. 36; para un caso español del 
escasa incidencia de este problema, sino porque a veces las mujeres podían «abrirse» manteniendo relaciones sexuales con otro hombre que no fuera su esposo, recuperando así la capacidad de proporcionar el débito conyugal. En 1206 una pareja fue separada por ser ella una mujer cerrada, y mientras que él podía volver a casarse, ella debía entrar en un monasterio, pues «unas mugeres de su parochia, buenas e honestas e sabias [quasdam matronas suae parochiae poruidas et honestas](...) dixieron que non auia instrumento natural» ${ }^{49}$. Pero esta mujer no parecía estar inclinada hacia la vida monástica y mantuvo relaciones sexuales con un hombre distinto a su marido. En este caso Inocencio III dictaminó que, en caso de que no hubiera hecho el voto de castidad solemne, el primer matrimonio debía restituirse, porque «aquel embargo no fue perdurable, el qual pudo ser tuelto sin miraglo de Dios por obra de omne e sin periglo del cuerpo» [quod impedimentum illud non erat perpetuum, quod praeter divinum miraculum per opus humanis absque corporale periculo potuit removeri $]_{\gg}{ }^{50}$. El rey castellano Alfonso X reguló en la cuarta partida los asuntos matrimoniales siguiendo las disposiciones eclesiásticas y, en el caso de las mujeres estrechas, reconoció la posibilidad de que un hombre distinto al marido devolviera a la esposa la capacidad de mantener relaciones sexuales. En esos casos eran los hombres quienes debían someterse a una prueba física para determinar con cuál de ellos estaba casada:

«Cerrada seyendo la muger, segund se dize en la ley ante desta de manera que la ouiessen departir de su marido, si acaesciesse que despues casasse con otro, que la conosciesse carnalmente, deue la departir del segundo marido, e tornarla al primero por que semeja que si conel auiesse fincado todavia, tambien la pudiera conoscer como el otro. Pero ante que los departan, deuen catar si son semejantes, o eguales en aquellos miembros que son menester para engendrar. E si entendieren que el marido primero non lo a mucho mayor que el segundo estonce la deuen tornar al primero marido. Mas si entendieren que el primero marido auia tan grande miembro, o en tal manera parado, que por ninguna manera non la pudiera conoscer sin grande peligro della, maguer

siglo XVII, Berhrend-Martínez, Edward. Female sexual potency in a Spanish church court, 1673-1735. Law and History Review. 2000; 24 (2): 297-330.

49. Decretales, n. 4, IV,15, 6, p. 61; Decretalium, n. 4, IV,15, 6, p. 706-707.

50. Decretales, n. 4, IV, 15, 6, p. 61; Decretalium, n. 4, IV, 15, 6, p. 706; Rousseau, Constance. Marriage, sexuality and family in the letters of Pope Innocent III (1198-1216). Toronto: University de Toronto; 1992, p. 155-160. 
conel ouisse fincado, por tal razon non la deuen departir del segundo marido, por que paresce manifiestamente, que el embargo duraua por siempre» ${ }^{51}$

A pesar de que hubiera diferentes maneras de abrir a las mujeres cerradas, la Iglesia tuvo que articular un procedimiento para separar a la pareja. La anulación podía solicitarse cuando alguna de las partes no podía proporcionar la deuda carnal y, de modo general, la Iglesia puso como condiciones la convivencia continuada de tres años, siete testigos que dieran fe de que el matrimonio no había sido consumado y una prueba física que demostrara la integridad del cuerpo femenino. Los exámenes de orina y las fumigaciones fueron otros modos de comprobar la virginidad ${ }^{52}$, pero lo cierto es que la inspección física pudo ser practicada incluso cuando el marido era acusado de impotencia. Este es el caso de una tal María, quien, tras ocho años de matrimonio con Andrés, solicitó que se le concediera el divorcio porque él era impotente. María probó su virginidad ante mujeres dignas de crédito y expertas en materia matrimonial [matronis bonae opinionis, fidde dignis, ac expertis in operere nuptiali ${ }^{53}$, pero el tribunal pidió pruebas complementarias: solicitó al párroco que buscara otra mujer que hubiera mantenido una relación sexual con Andrés, y ordenó a la pareja que hiciera penitencia para eliminar cualquier maleficio que pudiera impedir la confirmación sacramental. Todo ello no bastó, y Honorio III (1216-1227) solicitó el juramento de siete parientes.

La cantidad y calidad de los testigos son cuestiones fundamentales en cualquier tipo de pleito, y en los casos de anulación matrimonial por impo-

51. Las Siete Partidas. López, Gregorio, ed. y trad. Vol. 3. Salamanca; Andrea de Portonariis; 1555, Partida IV, Tit. VIII, Ley III, fol. 21V.

52. Green, Monica, ed. $y$ trad. The Trotula. An English translation of the medieval compemdium of women's medicine. Philadelfia: University of Pennsylvania; 2001, p. 95; Ketham, Johannes de.

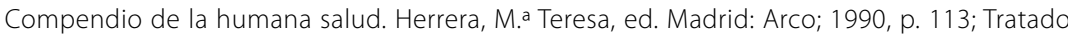
de patología, n. 39, p. 674; Magno, Alberto. The book of secrets. Best, Michael R; Brightman, Frank H, eds. York Beach, Maine: Samuel Weiser; 1999, p. 45; Kelly, n. 40, p. 30-31.

53. Decretales, n. 4, IV,15,7, p. 62; Decretalium, n. 4, IV,15,7, p. 1525. Sólo en Inglaterra hay documentados casos en los que unas mujeres realizaron la inspección física de hombres acusados de impotencia. Helmholz, R. H. Marriage litigation in medieval England. Cambridge: Cambridge University Press; 1974, p. 89; Pedersen, Frederik. Marriage disputes in medieval England. London: The Hambledon Press; 2000, p. 115-118; Donahue, Charles. Law, marriage, and society in the later Middle Ages. Arguments about marriage in five courts. Cambridge: Cambridge University Press; 2007, p. 277, 295-296 y 371. 
tencia también afectó a quienes daban fe de acuerdo a sus conocimientos ${ }^{54}$. La Iglesia no aceptó que se presentara un único declarante, y la fama pública era esencial para decidir un juicio ${ }^{55}$. Por ello Celestino III (1191-1198) estableció que los testigos en pleitos matrimoniales «deuen seer desechados por derecho de testimonio si ouieron mala fama ${ }^{56}$. La fama de las mujeres que inspeccionaban el cuerpo buscando signos de virginidad fue puesta en entredicho con frecuencia. Tanto en el caso del marido impotente como en el de la mujer cerrada de Inocencio III, el examen físico es realizado por unas mujeres que son calificadas como buenas, honestas y sabias. Si el peritaje de la virginidad fue realizado por parteras o por mujeres sin conocimiento experto sobre el cuerpo femenino, es una cuestión que la historiografía todavía no ha resuelto, y mientras Monica Green advierte de la importante diferencia entre ambos términos, Jacqueline Murray o Erwin Ackernecht parecen considerarlos intercambiables ${ }^{57}$.

Para discernir quiénes eran estas mujeres se debe atender a su formación y al alcance de su dictamen. Para anular los matrimonios en los que hombres o mujeres no podían cumplir con el débito carnal, la Iglesia estableció el peritaje físico femenino, pero las parteras ni tenían una educación regulada ni reconocimiento institucional. Sin parteras oficialmente reconocidas, la Iglesia utilizó el mismo criterio aplicado a otro tipo de testigos, poniendo el acento en la catadura moral del declarante. El coeficiente de credibilidad

54. En casos localizados en York parece que unas prostitutas fueron quienes inspeccionaron a un hombre que sufría de impotencia. Karras, Ruth M. Because the other is a poor woman she shall be called his wench: Gender, sexuality, and social status in late medieval England. In: Farmer, Sharon; Braun Pasternagk, Carol. eds. Gender and Difference in the Middle Ages. Minneapolis: University of Minnesota Press; 2003, p. 210-229 (221).

55. Schmugge, Ludwig. Matrimonial dispensation: How the penitentiary handled cases of impotence. In: Jaritz, Gerhard; Jørgensen, Torstein; Salonen, Kiri, eds. ... «Et usque ad ultimum terrae». The apostolic penitentiary in local contexts. Budapest: Central European University Press; 2007, p. 71-80; Rousseau, n. 50, p. 116-117.

56. Decretales, n. 4, II, 21, 7, p. 128; Decretalium, n. 4, II, 21, 7, p. 343.

57. Murray, Jacqueline. On the origins and role of «wise women» in causes for annulement on the grounds of male impotence. Journal of Medieval History. 1990; 16: 235-249 (242); Murray, Jacqueline. Impotence. In: Schaus, Margaret, ed. Women and gender in medieval Europe. An encyclopedia. New York: Routledge; 2006, p. 397-399; Green, Monica. Midwives. In: Schaus, Margaret, ed. p. 561-562; Green, Monica; Smail, Daniel L. The trial of Floreta d'Ays: Jews, christians and obstetrics in later medieval Marseille. Journal of Medieval History. 2008; 34: 185-211 (189, nota 12); Ackerknecht, Erwin H. Midwives as experts in court. Bulletin of the New York Academy of Medicine 1976; 52 (10): 1224-1228. Guardiola, Ginger L. Within and without: the social and medical worlds of the medieval midwife. 1000-1500. Ph. D. Dissertation, University of Colorado at Boulder; 2002, p. 313-315. 
era un elemento imprescindible para emitir una sentencia justa, de ahí que los calificativos de «buenas»y «honestas» fueran indispensables ${ }^{58}$. Un caso ocurrido en Siena coadyuva a aclarar quiénes eran estas mujeres, comparando el texto latino con la traducción castellana de finales del XIII o principios del XIV:

«Uno que auie nombre Guillem demandaua restitution de una manceba que dizien Guillelma de Sena, que dizie que era su muger. Ella respondie que non deuie[n] oyr sobresto, ca ella era uirgen e monia, e esto querie prouar como era uirgen e aduxo a mugeres las cuales la cataron e iuraron que era uirgen. Et contra aquellas mugeres dize aquel Guillem que eran de mala fama e non sabidas en aquel fecho, e esto querie prouar. Onde demandaron los juezes al papa si deuien reçebir estas prueuas las quales aduxieron la una parte e la otra, e tengan el negotio. Manda otrossi que pongan aquella manceba entanamientre en aquel monesterio en el qual entro e more segura miente, fata que sea yudgado por sententia que deua seer fecho; manda otrossi que otras mugeres honestas e sabias que caten si es uirgen, ca dize el decreto [que] la mano e el ojo de las parteras e de las que tal cosa catan muchas uezes son engannadas»
"Causam matrimonii, quae inter V. iuvenera et G. puellam Senonensem, quae se virginem et monacham profitetur, noscitur agilari, quia non ita instructam misisti, frater episcope, ut in ea usque ad calculum sententiae diffinitivae procedere libere valeremus, vobis remitimus plenius instruendam; discretioni vestrae Mandamus, quatenus eandem puellam ponatis interim in illo monasterio auctoritate apostolica, quod intravit, ut ibi secure valeat commorari, donec iudiciali sententia quid agi debeat decernatur, recepturi postmodum, prout iustitia dictaverit, non solum probationes viri, sicut protestatus fuerat, quas inducere voluerit contra mulieres illas, quae ad investigandum signa virginitatis ex parte puellae fuerunt introductae, verum etiam probationes alias hoc negotium contingentes, quas pars utralibet duxerit producendas. Et quia, ut dicit canon, saepe manus fallitur et oculus obstetricum, volumus et mandamus, ut adhuc honestas matronas providas et prudentes deputare curetis ad inquirendum, utrum dieta puella virginitatis privilegio sit munita, causamque nobis sub vestris sigillis instructam plenius remittatis ${ }^{59}$

58. Brundage, James. Judicial space: Female witnesses in canon law. Dumbarton Oaks Papers. 1998; 52:147-156 (152).

59. Decretales, n. 4, II,19,14, p. 96; Decretalium, n. 4, II,19,14, p. 314-315. La cursiva es mía. 
Este caso no está recogido en el lugar de las Decretales donde se podría esperar, el libro cuarto, que compila los decretos de anulación matrimonial. Se incluye en el libro segundo, dedicado a lo que hoy conocemos como Derecho Procesal, en donde se aclara quiénes eran estas mujeres y qué requisitos debían cumplir. Poco importa por qué la pareja no consumó el matrimonio; ella estaba en un monasterio y demostró con un examen físico ante un grupo de mujeres que era virgen. No fue difícil que el marido pusiera en duda el testimonio de estas mujeres. Honorio III (1216-1227) se vio obligado a aclarar que quienes debían inspeccionar por segunda vez a la mujer no sólo debían ser honestas, sino que también debían ser sabias (prudentes). Es decir, debían ser parteras quienes inspeccionaran la integridad vaginal. Para fundamentar su decisión tenía de su parte tanto la tradición eclesiástica como el derecho romano. El decreto al que alude - sin citarlo- es, sin duda, la carta de Cipriano a Pomponius, recogida por Graciano en su Decretum. Cipriano denunció la costumbre de algunas vírgenes de dormir con hombres, de modo que aunque pudieran demostrar mediante un examen físico su integridad corporal, no se debería dar crédito a dicha prueba, pues «manus obstetricum et oculus sepe fallantur» ${ }^{60}$. Por si el dictamen del Papa no queda suficientemente claro respecto a quién detenta el «oculus obstetricum», en la traducción medieval de las Decretales de Gregorio IX aparece una nota aclaratoria al respecto, especificando «que el ojo e las manos de las parteras muchas uezes se engannan». Caben pocas dudas de que las leyes eclesiásticas se elaboraron pensando en que fueran parteras quienes examinaran el cuerpo femenino, puesto que, además, su fuente proviene del derecho civil romano. En el Digesto, compilado en 533 d.C. por mandato de Justiniano, se recogieron los trabajos más influyentes de los juristas latinos antiguos. De ellos, el que en más ocasiones aparece citado es Ulpiano, de principios del siglo III, que recogió de la siguiente forma, la inspección física femenina por parte de parteras honestas:

«Parece que Rutilio Severo desea una cosa nueva, que a la mujer, que de él se había divorciado y que asegura que no está embarazada, se le ponga guarda; y por esto nadie se admirará, si también nosotros damos nuevo consejo y remedio. Así, pues, si persiste en la misma petición, es lo más conveniente que se elija la casa de una mujer muy honesta, á la cual vaya Domicia; y que allí

60. Decretum magistri Gratiani. Friedberg, Aemilius, ed. Graz: Akademische Druck-U. Verlagsanstalt; 1949, p. 1048-1049. 
la inspeccionen tres parteras probadas tanto por sus conocimientos como por su integridad, que por ti hayan sido escogidas; y si verdaderamente o todas, o dos, manifestaren que parece embarazada, entonces se habrá de persuadir a la mujer para que admita la guarda lo mismo que si ella lo hubiese pedido. Pero si luego no pariere, sepa el marido que esto afecta a la mala voluntad suya y a su estimación, de modo que no sin razón pueda considerarse que solicitó esto para inferir alguna injuria a la mujer; mas si o todas, o las más, manifestaren que no está embarazada, no habrá causa alguna para custodiarla» ${ }^{61}$.

Parece claro que este pasaje sirvió de inspiración a las Decretales, y que la Iglesia se estaba refiriendo a parteras. Pero no es obvio que todas las mujeres que daban fe ante un tribunal tuvieran el mismo grado de experiencia y conocimientos, por lo que no todas ellas podían ser calificadas como obstetrix ${ }^{62}$. Como ha demostrado Montserrat Cabré, los términos que se emplearon en la Península Ibérica para designar las actividades médicas femeninas están íntimamente relacionados con el campo semántico de mujer y madre. Estas mujeres fueron llamadas con frecuencia comadres o madrinas, a veces amas o, simplemente, mujeres ${ }^{63}$. A finales de la Edad Media aparecieron los primeros diccionarios en castellano al tiempo que los bilingües latín-castellano y latín-catalán, y en ellos se asimiló a la matrona con la madrina y la comadre ${ }^{64}$.

El Derecho Canónico se vio paulatinamente obligado a emplear palabras que aclararan qué requisitos debían cumplir las mujeres que ejercían estas labores de peritaje: la precisión lingüística era inexcusable cuando se ponía en duda el procedimiento en sí mismo. Si Gregorio VIII (oct. 1187-dic. 1187) ordenó que se creyera el testimonio de siete mujeres que aseguraban que

61. Cuerpo de derecho civil romano. Primera parte del digesto. García del Corral, Ildefonso L., trad., vol. II. Barcelona: Jaime Molinas; 1892, p. 219. La cursiva es mía. Evans-Grubbs, Judith. Women and the law in the Roman empire. A sourcebook on marriage, divorce and widowhood. London-New York: Routledge; 2002, p. 201.

62. Para un caso español del XVII en el que la pareja se separa por estrechez femenina y es inspeccionada en dos ocasiones por matronas D'Avray, David L. Medieval marriage. Symbolism and society. Oxford: Oxford University Press; 2005, p. 191-192.

63. Cabré, Montserrat. Women or healers? Household practices and the categories of health care in late medieval Iberia. Bulletin of the History of Medicine. 2008; 82: 18-51.

64. Palencia, Alfonso. Universal vocabulario en latín y romance. Madrid: Comisión permanente de la Asociación de Academias de la Lengua Española; 1967, p. cclviii (vol. 1), y cccxviii (vol. 2); Nebrija, Antonio. Diccionario latino español. Barcelona: Puvill, 1979; Nebrija, Antonio. García Busa, Gabriel. Diccionario latín-catalán y catalán-latín. Barcelona: Puvill; 1987. 
una mujer era virgen ${ }^{65}$, Honorio III (1216-1227) precisó que se trataba de parteras. Distintas decretales emplearon, sin embargo, el término matrona en vez de obstetrix, lo que obedece a dos circunstancias que no pueden ser pasadas por alto. En primer lugar hay que tener en cuenta que las mujeres no pudieron acceder a una educación médica formal, lo cual impedía que las parteras fueran reconocidas como profesionales. Al utilizar en las fuentes términos polisémicos como matrona, comadre, madrina, ama o simplemente mujer (honesta), que se aplicaban también a otras mujeres que no realizaban partos, se les reconocía su dedicación a una actividad, la partería, sin conferirle a ésta el estatus de profesión. En segundo lugar, se debe tener presente que la Iglesia debía asegurar prioritariamente la honestidad de los testigos, porque la confirmación o anulación de un matrimonio afectaba al orden social y sacramental.

No obstante, las sospechas sobre la honradez del testimonio de las parteras durante la inspección física estuvo a menudo presente, y su tendencia al engaño se convirtió en un topos del que la literatura médica se hizo eco. Chauliac además de suprimir la figura de la partera de la operación para la mujer cerrada, advirtió a los cirujanos de la necesidad de que contaran con la ayuda de mujeres honestas ${ }^{66}$. En el capítulo que dedicó a la impotencia masculina, detalla que antes de la anulación matrimonial lo habitual era que una matrona experta pasara la noche con los esposos y que, después, contara al médico lo que había visto:

«Es iuzgado tanbien que si los tales fuessen ayuntados por la fortuna que sea fecho el diuorcion por iusticia. mas porque la iusticia acostumbro cometer el examen a los medicos. por tanto se pone aqui el modo de examinar: E es que el medico auida la licencia de la iusticia examine primero la complexion e la composicion de los miembros generatiuos. dende aya matrona en tales cosas acostumbrada: e sea mandado que duerman juntamente por algunos dias essa matrona presente con ellos: e de a ellos species:

65. Decretales, n. 4, II,19,4, p. 87-88; Decretalium, n. 4, II,19,4, p. 307; Green, Monica. Documenting medieval women's medical pratice. In: García-Ballester, Luis. et. al., eds. Practical medicine from Salerno to the black death. Cambridge: Cambridge University Press; 1994, p. 322-352 (339).

66. En un caso catalán de 1245 en el que marido y mujer se acusan mutuamente de impotencia, dos «mujeres honestas» inspeccionaron el cuerpo de la esposa, y una tercera pasó tres noches con el matrimonio. McVaugh, Michael. Medicine before the plague. Practitioners and their patients in the Crown of Aragon, 1285-1345. Cambridge: Cambridge University Press; 2002, p. 204-205. 
e pimientas: e caliente a ello e vnte con azeites calientes e freguelos cerca del fuego de sarmiento: e mande a ellos fablar en vno e abraçarse. Dende aquello que ouiere visto recuente al medico. E quando el medico es bien enformado ante la iusticia de la verdad puede deponer. mas guardese que no sea engañado, porque muchos engaños en tales cosas se acostumbraron cometerse. E muy grand peligro es apartar aquellos que dios ayunto: saluo si muy iusta causa lo requiriesse» 67

La medicina debía contar con procedimientos específicos para estos casos no porque fueran especialmente frecuentes en el ejercicio clínico, sino porque permitían a los médicos convertirse en actores imprescindibles en el mantenimiento del orden social. Y para ello no dudaron en extender el descrédito sobre el saber y la honestidad de las parteras. Juan Fragoso ahondaba en ello en su Cirugía Universal (1581), al explicar qué cuestiones debían tener presentes aquellos cirujanos que testificaran en un tribunal. Para diagnosticar la virginidad femenina recurre a la experiencia de estas mujeres, aunque teme que pudieran mencionar el himen, un tejido cuya existencia niega y considera fruto de una creencia propia de personas incultas. Por ello, tras citar a grandes autoridades médicas, termina advirtiendo que «todo esto se ha dicho para que los juezes no crean siempre à las mugercillas quando declaran en esta materia ${ }^{68}$. Sin embargo, ellas fueron las únicas que, para salvaguardar la honestidad del cirujano, podían permanecer junto al matrimonio durante la noche para verificar la imposibilidad de consumarlo. Siguiendo a Chauliac, Fragoso muestra que los términos matrona, comadre y partera eran intercambiables:

«Aqui se note por curiosidad, que en caso dudoso, dispone el Derecho, que cohabiten tres años marido, y muger. Notese tambien de passo, que lo que dize Guido de la matrona, o comadre, que estè presente à ver los actos, y coitos de los dos para quitar la duda, no se tiene por honesto, ni seguro, y assi no ha lugar en el Derecho; porque dize. Fallax est oculus obstrectitiam. Quiere dezir, que es engañoso el ojo de las parteras» ${ }^{69}$

\footnotetext{
67. Guy de Chauliac, n. 31, fol. 59v. Cauliaco, n. 29, p. 386. La cursiva es mía.

68. Fragoso, Juan. Cirugia universal. Madrid: Viuda de Alonso Martin; 1627, p. 563b. La cursiva es mía.

69. Fragoso, n. 68, p. 563b.
} 


\section{Conclusiones}

En el siglo XIII la Iglesia se inspiró en las leyes romanas para establecer el papel de las parteras en ciertos asuntos legales como los procesos de divorcio. En su condición de peritos judiciales, era crucial que tuvieran una fama honorable, mientras que su pericia médica a menudo fue descalificada o dada por supuesta. De una parte eran imprescindibles para ejecutar procedimientos que exigían tocar los genitales femeninos, pero incidir en su sabiduría llamándolas obstetrices habría sido otorgarles una categoría profesional ajena a una práctica carente de formación reglada. Un índice del problema que supuso el reconocimiento profesional de las matronas es que cuando se crea Tribunal del Protomedicato en la España de los Reyes Católicos se incluye a las parteras entre las profesiones que pueden ser examinadas, pero poco después se les excluye de este reconocimiento profesional ${ }^{70}$. Sin embargo, las parteras se consideraron agentes imprescindibles en casos de impotencia. Que la Iglesia ordenara que fueran parteras quienes realizaran la inspección de la virginidad es una cuestión que se aclara en el citado capítulo dedicado a desgranar qué cualidades debían tener los testigos, pero con frecuencia se emplearon otros nombres que tendían a obviar los conocimientos que debían tener para realizar este peritaje. Es indiscutible la intersección de los campos semánticos de los términos partera y matrona, pero tampoco cabe duda de que en los casos particulares no siempre es fácil determinar si se exigía que las matronas reclutadas como expertas legales en materia ginecológica tuvieran la partería por oficio. La principal cualidad que habrían de ostentar tales matronas como peritas judiciales es la honestidad, y sólo ocasionalmente se reclama de ellas que sean «sabias». Los conocimientos y la práctica médica de estas mujeres fueron definidos por y para hombres ${ }^{71}$. Médicos y cirujanos no sólo subordinaron a sus funciones la actividad médica femenina, sino que trataron de soslayarla empleando términos diversos, jugando con las palabras con una evidente carga ideológica. Matrona, comadre, ama o

70. Eugenio Muñoz, Miguel. Recopilación de las leyes, pragmáticas, reales decretos y acuerdos del real Proto-Medicato. París-Valencia: Valencia; 1991, p. 107-110, 167-169 [reimp. de 1751]; Losana Méndez, José. La sanidad en la época del descubrimiento de América. Madrid: Cátedra; 1994, p. 64; Ortiz Gómez, Teresa. Protomedicato y matronas. Una relación al servicio de la cirugía. Dynamis. 1996; 16:109-120 (114).

71. Green, n. 26, p. 138. 
madrina son términos polisémicos que tuvieron implicaciones teológicas y significados que, más allá del oficio de la partería, afectaban a la urdimbre social medieval. Debido a la necesidad de establecer un procedimiento seguro para anular un matrimonio, el Derecho Canónico medieval con frecuencia utilizó el término matrona en vez de obstetrix, soslayando así la falta de instrucción médica formal de las mujeres, una carencia que las facultades de medicina se encargarían de perpetuar.

\section{Agradecimientos}

Este trabajo no hubiera sido posible sin el estímulo intelectual, apoyo bibliográfico y análisis crítico de Alejandro García Avilés con quien estaré en deuda permanente. Agradezco las sugerencias de los revisores anónimos, ya que han enriquecido enormemente el trabajo. 


\section{The «closed woman»: Female impotence in the Middle Ages and medical and legal inspection by midwives}

Paloma Moral de Calatrava...............................

1.- Introduction. 2.-Surgery for clausio matricis. 3.- Reputable women for female physical examinations. 4.-Conclusions.

ABSTRACT: Sexual relationships were established in the 13th century as a prerequisite for confirming or annulling a marriage. Therefore, when a woman was accused of not being physically able to satisfy her marital sexual duties, a group of women had to inspect the wife's body for signs of virginity. This paper focuses on the medical and legal role of midwives in these cases. Latin and vernacular medical texts show there were two schools of thought about who should perform surgery designed to recover her sexual lost potency: the midwife or the surgeon. The Church, however, did not always compel «closed or impotent women» to undergo this surgical intervention, presenting the separation of the couple as an alternative. It is not clear whether midwifes or simply reputable women had to examine the female body before the divorce in these cases. Mediaeval ecclesiastical decrees use terms such as matrona or woman, but the present paper demonstrates that these refer to midwives. 